\title{
Inhibition of Glioblastoma Cell Proliferation, Migration and Invasion by the Proteasome Antagonist Carfilzomib.
}

\author{
Zammam Areeb $^{a}$, Stanley S. Stylli ${ }^{a, b}$, Thomas, M. B. Ware ${ }^{a}$, Nicole C. Harris ${ }^{\text {c,d }}$, Lipi
} Shukla $^{\text {c,d }}$, Ramin Shayan ${ }^{\text {c,d }}$, Lucia Paradiso ${ }^{a}$, Bo Li ${ }^{\text {e,f }}$, Andrew P. Morokoff ${ }^{\text {a,b }}$, Andrew H. Kaye ${ }^{\mathrm{a}, \mathrm{b}}$ and Rodney B. Luwor ${ }^{\mathrm{a} *}$

${ }^{a}$ Department of Surgery, The University of Melbourne, The Royal Melbourne Hospital, Parkville, Victoria 3050, Australia.

${ }^{b}$ Department of Neurosurgery, The Royal Melbourne Hospital, Parkville, Victoria 3050, Australia.

${ }^{c}$ O'Brien Institute Tissue Engineering Centre, Regenerative Surgery Group, Fitzroy, Victoria, 3065, Australia.

${ }^{d}$ Department of Plastic and Reconstructive Surgery, St Vincent's Hospital, Fitzroy, Victoria, 3065, Australia.

${ }^{e}$ Paediatric Neurosurgery, Department of Paediatric Surgery, Qilu Hospital, Shandong University, 107\#, Wenhua Xi Road, Jinan, 250012, P.R. China.

${ }^{f}$ Brain Science Research Institute of Shandong University, Jinan 250012, P.R. China.

*Corresponding Author: Tel: +61 3 8344-3026; Fax: +61 3 9347-6488; E-mail: rluwor@unimelb.edu.au Level 5, Clinical Sciences Building, Department of Surgery, The University of Melbourne, The Royal Melbourne Hospital, Parkville, Victoria 3050, Australia. 


\begin{abstract}
Glioblastoma Multiforme is the most aggressive and lethal tumor of the central nervous system with limited treatment strategies on offer and as such the identification of effective novel therapeutic agents is paramount. To examine the efficacy of proteasome inhibitors we tested Bortezomib, Carfilzomib, Nafamostat mesylate, Gabexate mesylate and Acetylsalicylic acid on glioblastoma cell viability, migration and invasion. Both Bortezomib and Carfilzomib produced significant reduction of cell viability while Nafamostat mesylate, Gabexate mesylate and Acetylsalicylic acid did not. Subsequent testing showed that Carfilzomib significantly reduced cell viability at $\mathrm{nM}$ concentrations. Carfilzomib also reduced cell migration, secretion and activation of MMP2 and also cell invasion of all 4 glioblastoma cells tested. In summary, Carfilzomib represents a novel, yet FDA-approved agent for the treatment of glioblastoma multiforme.
\end{abstract}

Keywords: Glioblastoma Multiforme; Carfilzomib; Proteasome; Migration; Invasion; MMP2. 


\section{Background}

Glioblastoma multiforme (GBM), also known as grade IV astrocytoma, is the most common form of malignant brain tumor and currently has a median survival time of approximately 15 months with standard treatment (1), and a recurrence rate of $72 \%$ before 17 months (2). The current standard treatment of GBM is surgery, followed by radiation and chemotherapy using temozolomide $(3,4)$. Although the standard treatment for GBM has improved survival times the prognosis is still extremely poor (5). Resistance to temozolomide and radiotherapy is extremely common, which heightens the need to improve patient survival and to seek novel therapeutics for the treatment of $\operatorname{GBM}(6,7)$.

Tyrosine kinase activity is a major driver of cancer progression and there is evidence linking aberrant receptor tyrosine kinase (RTK) activation and the degree of proliferation (8), growth (9), invasion (10), migration (11), apoptosis (12) and patient outcome (13) in GBM. However, clinical trials using various tyrosine kinase inhibitors as a front-line therapeutic option in primary or recurrent GBM (14-17) or combined with temozolomide (18-20) have generally yielded unsatisfactory outcomes. These dismal performances by tyrosine kinase inhibitors have been noted to be due to a diverse range of reasons such as 1) GBM cells are able to adapt their dependency on alternative pathways (21), 2) The heterogeneous nature of GBM also allows for an inevitable resistant cell population to remain after treatment (22), 3) RTK mutation differences between GBM patients (23), 4) Upstream inhibition may not lead to inhibition of downstream drivers of tumorigenesis (24) and 5) the RTK inhibitor's benefit is blocked as RTK mutations that exist in other cancers are absent in GBM (25). These results indicate the necessity to identify novel targets for the treatment of GBM.

A viable cellular target for GBM that has shown promising results in other cancers (26) is the $26 \mathrm{~S}$ proteasome. The $26 \mathrm{~S}$ proteasome is an intracellular protease which degrades proteins via the ubiquitin pathway (27). Cancer cells have a high turnover of proteins due to translation of dysfunctional proteins brought on by their rapid growth (28). Furthermore, key signalling pathways in GBM converge upon and involve the $26 \mathrm{~S}$ proteasome (29). Consequently, proteasome inhibition results in the stabilization and accumulation of polyubiquitin-tagged proteins, leading to the in-activation of proliferation, cell cycle arrest, and the establishment of apoptotic cell death $(30,31)$. Thus, this raises the possibility of the $26 \mathrm{~S}$ proteasome as a potentially viable target for GBM-based therapy.

Bortezomib is the first proteasome inhibitor to be approved and is used clinically for multiple myeloma (32). The mechanism of action involves the targeting of the $\beta$-subunit of the proteasome through reversible binding (33). Bortezomib has produced positive results in 
in vitro studies utilizing GBM cell lines $(34,35)$, however phase II trials with GBM patients have not been as promising $(34,36)$. In contrast to Bortezomib, which has a boronate chemical structure, Carfilzomib is an epoxyketone and is highly selective for and irreversibly inhibits the $\beta 5$ subunit of the 20S proteasome (37). Interestingly, although Carfilzomib has been approved for use in cases of multiple myeloma (38), the potential for adopting Carfilzomib in the GBM clinical setting has rarely been investigated with no study as yet evaluating an in-depth analysis on the anti-tumorigenic impact of Carfilzomib in GBM. This is the case despite Carfilzomib producing an increased efficacy compared to Bortezomib and also the ability for overcoming Bortezomib resistance in multiple myeloma cell lines (39) . In this study, we analysed the ability of Carfilzomib to suppress GBM cell viability, MMP2 secretion, migration and invasion using several GBM cell lines and successfully demonstrate the potential therapeutic value of Carfilzomib in reducing GBM tumorigenesis. 


\section{Materials and Methods}

Cell, Cell Culture and Inhibitors: The GBM cell lines U87MG and LN229 were purchased from ATCC, while the U87-EGFRvIII cell line was a kind gift from the San Diego Branch of the Ludwig Institute for Cancer Research. The primary GBM cell line, \#41 was originally derived from a pathological confirmed GBM patient at the Royal Melbourne Hospital and subsequently modified from neurosphere non-adherent cells to adherent cells grown in monolayer. Use of this cell line in the laboratory was approved by the Melbourne Health Human Research and Ethics Committee (HREC 2012.219). All cells were maintained in Dulbecco's Modified Eagle's Medium (Life Technologies) contained 10\% foetal bovine serum (FBS) (DKSH), $2 \mathrm{mM}$ glutamine, 100U/ml penicillin and $100 \mu \mathrm{g} / \mathrm{ml}$ streptomycin (Invitrogen). Cells were incubated in a humidified atmosphere of $10 \% \mathrm{CO}_{2}$ at $37^{\circ} \mathrm{C}$. All 5 proteasome inhibitors (Bortezomib, Carfilzomib, Nafamostat mesylate, Gabexate mesylate and Acetylsalicylic acid) were purchased from Selleck Chemicals.

Cell Viability Assays. Cells were plated in 96-well plates and allowed to adhere overnight. Triplicate wells were treated with varying concentrations of inhibitors where indicated for 72 hr. Cell were then lysed and cell viability relative to a vehicle control was determined using a commercially available Cell Titer-Glo kit (Promega) following manufacturer's instructions. Cell lysates were read on a bioluminometer.

MMP Expression Analysis. Cells $\left(1 \times 10^{5}\right)$ were seeded in 6-well plates and allowed to adhere overnight. Conditioned media was removed at $72 \mathrm{hr}$ following subsequent culturing of cells in Optimem media without serum (Life Technologies) in the presence of increasing concentrations of Carfilzomib $(0-1 \mu \mathrm{M})$. Conditioned media was then assessed for pro and active levels of MMP2 and MMP9 by gelatinolytic zymography by diluting 1:1 in TrisGlycine buffer and loaded into the wells of a 15 well zymogram gel after normalising for equal protein concentrations in cell lysates using the Pierce protein estimation kit (Thermo Fisher Scientific Inc.). Gels were subsequently incubated in Zymogram Renaturing Buffer (30 min), Zymogram Developing Buffer (overnight) and washed with distilled water. Gels were then incubated in Safety Blue Solution (1 hr) to visualize gelatinolytic activity with negative staining indicative of enzyme activity. 
Migration Assays. The migration capacity of GBM cells were examined using the xCELLigence system (ACEA Biosciences Inc.). Cells $\left(2 \times 10^{4}\right)$ were seeded with $2 \%$ serum DMEM in the top chamber of a CIM-16 plate in the absence or presence of Carfilzomib while the cell-free bottom chamber contained DMEM with $10 \%$ serum in order to create an attractant gradient. The migration rate was assessed by measuring electrical impedance along the gold coated underside of the membrane which separated the two chambers. A greater level of electrical impedance was determined as an amplified migratory rate as analysed on the RTCA Analyser over a $72 \mathrm{hr}$ period (ACEA Biosciences Inc.).

Invasion Assay. The ability of Carfilzomib to inhibit the invasiveness of U87MG, U87EGFRvIII, LN229 and \#41 cells was assessed using the Cultrex® 96 Well 3D Spheroid BME Cell Invasion Assay (Trevigen). The spheroid and invasion matrix components were prepared according to the manufacturer's instructions. Cells $\left(5 \times 10^{2}\right)$ in DMEM and spheroid matrix were added into each well of the 3D Culture Spheroid Formation Plate and then centrifuged at $200 \mathrm{~g}$ for $3 \mathrm{~min}$ at $4^{\circ} \mathrm{C}$. Cells were left to incubate for $72 \mathrm{hr}$ at $37^{\circ} \mathrm{C}$ to allow for spheroid formation, before invasion matrix was added and a subsequent centrifugation at $300 \mathrm{~g}$ for 5 $\min$ at $4^{\circ} \mathrm{C}$ was performed. The plate was left to incubate for $1 \mathrm{hr}$ at $37^{\circ} \mathrm{C}$ to enhance gel formation of the invasion matrix. DMEM $\pm 1 \mu \mathrm{M}$ Carfilzomib was added into each well and images of the spheroids were acquired every $24 \mathrm{hr}$. Images were subsequently analysed with the software Image $\mathrm{J}$ (v1.50d) and the degree of invasiveness was measured as the total area of the spheroid's reach.

\section{Statistical Analysis}

For all cell viability assays, the untreated (control) cell viability reading was set at $100 \%$. The treated cell viability reading was then taken as a percentage compared to the control value. Statistical analysis was performed using a two sided student's t-test. Significance was determined as $\mathrm{p}<0.05$. 


\section{Results:}

Carfilzomib Inhibits Cell Viability of GBM cell lines: To evaluate targeting of the proteasome as a potential treatment strategy in GBM, we first tested the efficacy of several proteasome inhibitors in a cell viability assay with 3 GBM cell lines (U87MG, U87EGFRvIII and LN229). Bortezomib and Carfilzomib $(10 \mu \mathrm{M})$ produced the greatest inhibition against all 3 cell lines tested reducing cell viability by greater than $85 \%$ and $90 \%$ respectively in all 3 cell lines. Nafamostat mesylate, Gabexate mesylate and Acetylsalicylic acid (all at $10 \mu \mathrm{M}$ ) did not significantly reduce viability of any of the 3 cell lines tested and in fact enhanced cell viability compared to control treated cells in some cases (Fig 1A). We next evaluated the efficacy of Carfilzomib on an early passage patient-derived primary GBM cell line (\#41) and the 3 established cell lines at lower concentrations. Carfilzomib significantly inhibited the cell viability of U87MG, U87-EGFRvIII, LN229 and \#41 at concentrations as low as $10 \mathrm{nM}$ by greater than $50 \%$ (Fig 1B).

\section{Carfilzomib Inhibits Cell Migration of GBM cell lines:}

As cell migration is a important characteristic of GBM lethality we next examined whether Carfilzomib could reduce GBM cell migration using the xCELLigence real-time migration system. Carfilzomib could significantly inhibit cell migration in 4 out of 4 GBM cell lines tested (U87MG, U87-EGFRvIII, LN229, \#41) at a $10 \mathrm{nM}$ dose after $72 \mathrm{hr}(\mathrm{p}<0.05)$ (Fig 2).

\section{Carfilzomib Inhibits Cell Secretion of MMP2 in GBM cell lines:}

MMPs are secreted from tumour cells leading to MMP-mediated degradation of the extracellular matrix allowing GBM cells to invade into surrounding brain tissue. As we observed that Carfilzomib could inhibit GBM cell migration, we next examined the effect of Carfilzomib treatment on the secretion and activation of pro-invasive MMP molecules in the GBM cell lines. A clear reduction in secreted pro MMP2 was observed in all 4 cell lines tested following $72 \mathrm{hr}$ of $1 \mu \mathrm{M}$ carfilzomib treatment (Fig 3). A reduction in the activation of MMP2 was also observed at this concentration for all the cell lines. Carfilzomib was also able to significantly inhibit pro MMP2 secretion and subsequent activation at a lower concentration of $0.1 \mu \mathrm{M}$, in the U87MG and LN229 cell lines (Fig 3).

\section{Carfilzomib Inhibits Cell Invasion of GBM cell lines:}

Mortality from GBM is attributed to its invasive nature and destruction of surrounding brain tissue (40). Therefore identifying novel agents that can inhibit the invasive 
characteristics of GBM cells is vitally important. Thus we next examined the ability of Carfilzomib to suppress the invasive capacity of our 4 GBM cell lines using an in vitro 3D invasion assay. In all 4 cell lines, $1 \mu \mathrm{M}$ of Carfilzomib significantly reduced the invasive capacity of cells over the 15 day experiment when compared to control treated cells $(\mathrm{p}<0.05)$ (Fig 4). All control cells showed significantly greater invasion after 15 days compared to day 1 with LN229 cells displaying almost 12-fold greater invasion compared to day 1. As expected, the U87-EGFRvIII cell line that expresses the constitutively active truncated EGFRvIII variant displayed a greater invasive phenotype than the parental U87MG cell line across the 15 day experiment. The addition of Carfilzomib significantly reduced this invasive potential (Fig 4B), indicating that Carfilzomib could reduce the invasive capabilities of all 4 glioblastoma cell lines tested. 


\section{Discussion:}

Novel treatment strategies are urgently required for GBM patients as the current standard of care treatment involving radiotherapy and temozolomide following surgical resection only enhances patient survival to approximately 15 months post diagnosis. Other treatment strategies have been pursued to improve the outcomes of GBM patients with the most common being the evaluation of kinase inhibitors including those that target the Epidermal Growth Factor Receptor (EGFR) or the Vascular Endothelial Growth Factor Receptor (VEGFR) systems. However, to date, none have shown additional benefit and all have shown additional systemic toxicity (41-43).

Targeting the proteasome represents a novel molecular pathway in GBM treatment with the majority of assessment of this class of inhibitor arising from studies on Bortezomib (Velcade). Bortezomib has been successfully shown to inhibit GBM cell proliferation and animal xenograft growth by triggering apoptosis and autophagy (44-49). However, despite this promise in the laboratory and the success of Bortezomib in treating patients with multiple myeloma, clinical trials evaluating Bortezomib in the GBM setting have been disappointing. The study by Odia and colleagues demonstrated that the combination of tamoxifen and Bortezomib has a promising toxicity profile, but ultimately delivered no therapeutic benefit in patients with recurrent malignant gliomas (36). Likewise, another Phase II study reported a lack of benefit from a combination of Bortezomib and vorinostat in recurrent GBM patients (34). Other proteasome inhibitors have also been FDA-approved for the treatment of various diseases including cancer such as Carfilzomib which is authorized for the use in refractory/relapsed multiple myeloma patients. However, very little is known about the ability of these agents to inhibit GBM progression, and thus, we evaluated the antitumorigenic effects of these agents on several GBM cell lines.

In this study we identified for the first time that Carfilzomib is a potent inhibitor of GBM cell proliferation, migration and invasion. Interestingly, others have reported previously that Carfilzomib is more potent in producing anti-tumor effects using non GBM cell lines compared to Bortezomib (50). However, we observed that Carfilzomib and Bortezomib were equally potent in inhibiting the cell proliferation of GBM cell lines including a primary, early passage patient-derived GBM cell line at the one concentration $(10 \mu \mathrm{M})$ tested in this current study. Furthermore, Carfilzomib and Bortezomib were strikingly more potent than the 3 other proteasome inhibitors (Nafamostat Mesylate (NM), Gabexate mesylate (GM), or Acetylsalicylic acid (AA; Aspirin) at the same concentration tested on the same panel of GBM cell lines. 
Of note was the ability of Carfilzomib to equally inhibit the proliferation, migration and invasion of cells expressing the EGFRvIII compared to the parental U87MG cell line. EGFRvIII is a truncated, constitutively active variant of EGFR and is expressed in approximately 30-50\% of GBM (51). Importantly, EGFRvIII has been proposed as a critical mediator of treatment resistance (52-54) and its constitutive active properties have been long considered a key driver of anti-apoptotic mechanisms and subsequently is known as a prosurvival tumor-specific receptor $(52,54,55)$. However, in our current study, Carfilzomib displayed similar anti-proliferative, anti-migratory and anti-invasive effects on both the U87EGFRvIII and the parental U87MG cell lines, suggesting that Carfilzomib may have some therapeutic benefit for GBM patients that are positive for EGFRvIII expression. This was achieved despite a previous report observing that the U87MG and U87-EGFRvIII cell lines significantly differed in proteasome subunit expression (56). Interestingly, Bortezomib also inhibited the cell viability of U87MG-EGFRvIII cells in our study.

One of the most characteristic features of GBM cells is their ability to invade into distal areas of the brain. Their highly infiltrative nature is strongly associated with elevated mortality rates in patients with GBM. The matrix metalloproteinase (MMPs) family members MMP2 and MMP9 are secreted by tumor cells to assist with breaking down extracellular matrix allowing for the enhanced invasiveness of cells (57-59). Therefore, a critical feature of a successful inhibitor of GBM progression is the ability of the agent to block MMP secretion and therefore inhibit GBM invasion. We show here that Carfilzomib could successfully reduce the secretion and subsequent activation of MMP2 in all 4 GBM cell lines tested. This correlated strongly with our findings that Carfilzomib could also inhibit 3D in vitro cell invasion in all 4 GBM cell lines tested.

Whether, Carfilzomib is capable of inhibiting GBM growth and invasion in animal models is not known and whether it can cross a compromised blood brain barrier in GBM patients to elicit an anti-tumor response is yet to be determined. Interestingly, it was suggested that Bortezomib's lack of activity in glioblastoma patients may be due in part to its suspected inability to penetrate the blood-brain barrier in these patients $(34,36)$. In this study, we did not assess whether Carfilzomib was able to cross the blood-brain barrier. However, another study demonstrated the successful distributed of the proteasome inhibitor salinosporamide A (ML858) to the brains of mice which led to substantial inhibition of the proteasome (60), suggesting that proteasome inhibitors including Carfilzomib may indeed be a viable treatment option for glioblastoma patients. 
Overall however, we have demonstrated that Carfilzomib displayed similar inhibitory effects on GBM cell viability to that of Bortezomib but was far more potent than the other proteasome inhibitors utilised in this study. In addition, Carfilzomib successfully reduced both the in vitro migration and invasive capabilities of all GBM cell lines tested. In summary, our current data support the view that the second-generation proteasome inhibitor Carfilzomib should be considered a potential therapeutic agent for the treatment of GBM. 


\section{Figure Legend:}

Figure 1. Carfilzomib inhibits cell viability of several glioblastoma cell lines: A. U87MG (i), U87-EGFRvIII (ii) and LN229 (iii) glioblastoma cells were seeded into 96-well plates in triplicate and following overnight incubation were treated with $10 \mu \mathrm{M}$ of Bortezomib, Carfilzomib, Nafamostat Mesylate (NM), Gabexate mesylate (GM), or Acetylsalicylic acid (AA; Aspirin) for $72 \mathrm{~h}$ to assess their effect on cell viability. B. U87MG (i), U87-EGFRvIII (ii), LN229 (iii) and \#41 primary (iv) glioblastoma cells were treated with increased concentrations of Carfilzomib for $72 \mathrm{~h}$. Cell viability was determined using a commercially available Cell Titer-Glo kit and samples read on a bioluminometer. Data is expressed as \% viability compared to untreated control cells \pm S.D.

Figure 2. Carfilzomib inhibits cell Migration of several glioblastoma cell lines: U87MG (i), U87-EGFRvIII (ii), LN229 (iii) and \#41 (iv) glioblastoma cells were seeded into CIM-16 xCELLigence plates and treated with $\pm 10 \mathrm{nM}$ of Carfilzomib in triplicate. Cell migration was then assessed over $72 \mathrm{hr}$ measuring relative mean impedance (cell index) for control treated $(\square)$ and Carfilzomib treated cells (ם). Data shown is mean relative percentage migration from duplicate wells, $\pm \mathrm{SD}(*, \mathrm{p}<0.05)$.

Figure 3. Carfilzomib inhibits cell secretion and activation of MMP2 in several glioblastoma cell lines: U87MG, U87-EGFRvIII, LN229 and \#41 glioblastoma cells were seeded into 6-well plates and following overnight incubation, cells where treated with $\pm 1 \mu \mathrm{M}$ of Carfilzomib in serum-free media. Following a subsequent $72 \mathrm{hr}$ period, assessments of pro- and active MMP2 levels in conditioned media was performed by gel zymography.

Figure 4. Carfilzomib inhibits cell Invasion in several glioblastoma cell lines: U87MG, U87MG-EGFRvIII, LN229 and \#41 glioblastoma cells were seeded into 3D invasion assay plates as described in Materials and Methods and treated with $\pm 1 \mu \mathrm{M}$ of Carfilzomib in triplicate. A. Images were taken every day for 15 days with cell invasion images displayed for day 1 and day 15. B. Relative invasion after 15 days of cells treated with control ( $\square$ ) and Carfilzomib (ם). Data shown is relative invasion from triplicate wells, \pm SD where control treated cells at day 1 is $=1(*, p<0.05)$. 


\section{Conflict Statement:}

The authors declare no conflict of interest or financial benefit from this publication. 


\section{References}

1. Adamson C, Kanu OO, Mehta Al, Di C, Lin N, Mattox AK, et al. Glioblastoma multiforme: a review of where we have been and where we are going. Expert Opin Investig Drugs. 2009 Aug;18(8):1061-83.

2. Milano MT, Okunieff P, Donatello RS, Mohile NA, Sul J, Walter KA, et al. Patterns and timing of recurrence after temozolomide-based chemoradiation for glioblastoma. Int J Radiat Oncol Biol Phys. 2010 Nov 15;78(4):1147-55.

3. Stupp R, Hegi ME, Mason WP, van den Bent MJ, Taphoorn MJ, Janzer RC, et al. Effects of radiotherapy with concomitant and adjuvant temozolomide versus radiotherapy alone on survival in glioblastoma in a randomised phase III study: 5-year analysis of the EORTC-NCIC trial. Lancet Oncol. 2009 May;10(5):459-66.

4. Stupp R, Mason WP, van den Bent MJ, Weller M, Fisher B, Taphoorn MJ, et al. Radiotherapy plus concomitant and adjuvant temozolomide for glioblastoma. N Engl J Med. 2005 Mar 10;352(10):987-96.

5. Gan HK, Rosenthal MA, Cher L, Dally M, Drummond K, Murphy M, et al. Management of glioblastoma in Victoria, Australia (2006-2008). J Clin Neurosci. 2015 Sep;22(9):1462-6.

6. Burkhardt JK, Hofstetter CP, Santillan A, Shin BJ, Foley CP, Ballon DJ, et al. Orthotopic glioblastoma stem-like cell xenograft model in mice to evaluate intra-arterial delivery of bevacizumab: from bedside to bench. J Clin Neurosci. 2012 Nov;19(11):1568-72.

7. Luwor RB, Stylli SS, Kaye AH. The role of Stat3 in glioblastoma multiforme. J Clin Neurosci. 2013 Jul;20(7):907-11.

8. Zundel W, Schindler C, Haas-Kogan D, Koong A, Kaper F, Chen E, et al. Loss of PTEN facilitates HIF-1-mediated gene expression. Genes Dev. 2000 Feb 15;14(4):391-6.

9. Engebraaten $\mathrm{O}$, Bjerkvig R, Pedersen PH, Laerum OD. Effects of EGF, bFGF, NGF and PDGF(bb) on cell proliferative, migratory and invasive capacities of human brain-tumour biopsies in vitro. Int J Cancer. 1993 Jan 21;53(2):209-14.

10. El-Obeid A, Bongcam-Rudloff E, Sorby M, Ostman A, Nister M, Westermark B. Cell scattering and migration induced by autocrine transforming growth factor alpha in human glioma cells in vitro. Cancer Res. 1997 Dec 15;57(24):5598-604.

11. Nazarenko I, Hede SM, He X, Hedren A, Thompson J, Lindstrom MS, et al. PDGF and PDGF receptors in glioma. Ups J Med Sci. 2012 May;117(2):99-112.

12. Linger RM, Keating AK, Earp HS, Graham DK. Taking aim at Mer and Axl receptor tyrosine kinases as novel therapeutic targets in solid tumors. Expert Opin Ther Targets. 2010 Oct;14(10):1073-90.

13. Mizoguchi M, Betensky RA, Batchelor TT, Bernay DC, Louis DN, Nutt CL. Activation of STAT3, MAPK, and AKT in malignant astrocytic gliomas: correlation with EGFR status, tumor grade, and survival. J Neuropathol Exp Neurol. 2006 Dec;65(12):1181-8.

14. Balana C, Gil MJ, Perez P, Reynes G, Gallego O, Ribalta T, et al. Sunitinib administered prior to radiotherapy in patients with non-resectable glioblastoma: results of a phase II study. Target Oncol. 2014 Dec;9(4):321-9.

15. Iwamoto FM, Lamborn KR, Robins HI, Mehta MP, Chang SM, Butowski NA, et al. Phase II trial of pazopanib (GW786034), an oral multi-targeted angiogenesis inhibitor, for adults with recurrent glioblastoma (North American Brain Tumor Consortium Study 06-02). Neuro Oncol. 2010 Aug;12(8):855-61.

16. Thiessen B, Stewart C, Tsao M, Kamel-Reid S, Schaiquevich P, Mason W, et al. A phase I/II trial of GW572016 (lapatinib) in recurrent glioblastoma multiforme: clinical outcomes, pharmacokinetics and molecular correlation. Cancer Chemother Pharmacol. 2010 Jan;65(2):353-61. 
17. Uhm JH, Ballman KV, Wu W, Giannini C, Krauss JC, Buckner JC, et al. Phase II evaluation of gefitinib in patients with newly diagnosed Grade 4 astrocytoma: Mayo/North Central Cancer Treatment Group Study N0074. Int J Radiat Oncol Biol Phys. 2011 Jun 1;80(2):347-53.

18. Peereboom DM, Shepard DR, Ahluwalia MS, Brewer CJ, Agarwal N, Stevens GH, et al. Phase II trial of erlotinib with temozolomide and radiation in patients with newly diagnosed glioblastoma multiforme. J Neurooncol. 2010 May;98(1):93-9.

19. Reardon DA, Nabors LB, Mason WP, Perry JR, Shapiro W, Kavan P, et al. Phase I/randomized phase II study of afatinib, an irreversible ErbB family blocker, with or without protracted temozolomide in adults with recurrent glioblastoma. Neuro Oncol. 2015 Mar;17(3):430-9.

20. Zustovich F, Landi L, Lombardi G, Porta C, Galli L, Fontana A, et al. Sorafenib plus daily lowdose temozolomide for relapsed glioblastoma: a phase II study. Anticancer Res. 2013 Aug;33(8):3487-94.

21. Endersby R, Baker SJ. PTEN signaling in brain: neuropathology and tumorigenesis. Oncogene. 2008 Sep 18;27(41):5416-30.

22. Denysenko T, Gennero L, Juenemann C, Morra I, Masperi P, Ceroni V, et al. Heterogeneous phenotype of human glioblastoma: in vitro study. Cell Biochem Funct. 2014 Mar;32(2):164-76.

23. Roth $\mathrm{P}$, Weller $\mathrm{M}$. Challenges to targeting epidermal growth factor receptor in glioblastoma: escape mechanisms and combinatorial treatment strategies. Neuro Oncol. 2014 Oct;16 Suppl 8:viii14-9.

24. Nakada M, Kita D, Watanabe T, Hayashi Y, Hamada J. Mechanism of chemoresistance against tyrosine kinase inhibitors in malignant glioma. Brain Tumor Pathol. $2014 \mathrm{Jul} ; 31$ (3):198-207.

25. Vivanco I, Robins HI, Rohle D, Campos C, Grommes C, Nghiemphu PL, et al. Differential sensitivity of glioma- versus lung cancer-specific EGFR mutations to EGFR kinase inhibitors. Cancer Discov. 2012 May;2(5):458-71.

26. Kouroukis TC, Baldassarre FG, Haynes AE, Imrie K, Reece DE, Cheung MC. Bortezomib in multiple myeloma: systematic review and clinical considerations. Curr Oncol. 2014 Aug;21(4):e573603.

27. Chitra S, Nalini G, Rajasekhar G. The ubiquitin proteasome system and efficacy of proteasome inhibitors in diseases. Int J Rheum Dis. 2012 Jun;15(3):249-60.

28. Obeng EA, Carlson LM, Gutman DM, Harrington WJ, Jr., Lee KP, Boise LH. Proteasome inhibitors induce a terminal unfolded protein response in multiple myeloma cells. Blood. 2006 Jun 15;107(12):4907-16.

29. Vlachostergios PJ, Voutsadakis IA, Papandreou CN. The shaping of invasive glioma phenotype by the ubiquitin-proteasome system. Cell Commun Adhes. 2013 Oct;20(5):87-92.

30. Dalton WS. The proteasome. Semin Oncol. 2004 Dec;31(6 Suppl 16):3-9; discussion 33.

31. Orlowski RZ, Kuhn DJ. Proteasome inhibitors in cancer therapy: lessons from the first decade. Clin Cancer Res. 2008 Mar 15;14(6):1649-57.

32. Grosicki S, Barchnicka A, Jurczyszyn A, Grosicka A. Bortezomib for the treatment of multiple myeloma. Expert Rev Hematol. 2014 Apr;7(2):173-85.

33. Styczynski J, Olszewska-Slonina D, Kolodziej B, Napieraj M, Wysocki M. Activity of bortezomib in glioblastoma. Anticancer Res. 2006 Nov-Dec;26(6B):4499-503.

34. Friday BB, Anderson SK, Buckner J, Yu C, Giannini C, Geoffroy F, et al. Phase II trial of vorinostat in combination with bortezomib in recurrent glioblastoma: a north central cancer treatment group study. Neuro Oncol. 2012 Feb;14(2):215-21.

35. Vlachostergios PJ, Papandreou CN. Efficacy of low dose temozolomide in combination with bortezomib in U87 glioma cells: a flow cytometric analysis. Arch Med Sci. 2015 Apr 25;11(2):307-10.

36. Odia Y, Kreisl TN, Aregawi D, Innis EK, Fine HA. A phase II trial of tamoxifen and bortezomib in patients with recurrent malignant gliomas. J Neurooncol. 2015 Oct;125(1):191-5.

37. Fostier K, De Becker A, Schots R. Carfilzomib: a novel treatment in relapsed and refractory multiple myeloma. Onco Targets Ther. 2012;5:237-44. 
38. Moreau P, Richardson PG, Cavo M, Orlowski RZ, San Miguel JF, Palumbo A, et al. Proteasome inhibitors in multiple myeloma: 10 years later. Blood. 2012 Aug 2;120(5):947-59.

39. Kuhn DJ, Chen Q, Voorhees PM, Strader JS, Shenk KD, Sun CM, et al. Potent activity of carfilzomib, a novel, irreversible inhibitor of the ubiquitin-proteasome pathway, against preclinical models of multiple myeloma. Blood. 2007 Nov 1;110(9):3281-90.

40. Drappatz J, Norden AD, Wen PY. Therapeutic strategies for inhibiting invasion in glioblastoma. Expert Rev Neurother. 2009 Apr;9(4):519-34.

41. Johnson DR, Chang SM. Recent medical management of glioblastoma. Adv Exp Med Biol. 2012;746:26-40.

42. Omuro A, DeAngelis LM. Glioblastoma and other malignant gliomas: a clinical review. JAMA. 2013 Nov 6;310(17):1842-50.

43. van den Bent MJ, Hegi ME, Stupp R. Recent developments in the use of chemotherapy in brain tumours. Eur J Cancer. 2006 Mar;42(5):582-8.

44. Balyasnikova IV, Ferguson SD, Han Y, Liu F, Lesniak MS. Therapeutic effect of neural stem cells expressing TRAIL and bortezomib in mice with glioma xenografts. Cancer Lett. 2011 Nov 28;310(2):148-59.

45. Foti C, Florean C, Pezzutto A, Roncaglia P, Tomasella A, Gustincich S, et al. Characterization of caspase-dependent and caspase-independent deaths in glioblastoma cells treated with inhibitors of the ubiquitin-proteasome system. Mol Cancer Ther. 2009 Nov;8(11):3140-50.

46. Kahana S, Finniss S, Cazacu S, Xiang C, Lee HK, Brodie S, et al. Proteasome inhibitors sensitize glioma cells and glioma stem cells to TRAIL-induced apoptosis by PKCepsilon-dependent downregulation of AKT and XIAP expressions. Cell Signal. 2011 Aug;23(8):1348-57.

47. Unterkircher T, Cristofanon S, Vellanki SH, Nonnenmacher L, Karpel-Massler G, Wirtz CR, et al. Bortezomib primes glioblastoma, including glioblastoma stem cells, for TRAIL by increasing tBid stability and mitochondrial apoptosis. Clin Cancer Res. 2011 Jun 15;17(12):4019-30.

48. Yin D, Zhou H, Kumagai T, Liu G, Ong JM, Black KL, et al. Proteasome inhibitor PS-341 causes cell growth arrest and apoptosis in human glioblastoma multiforme (GBM). Oncogene. 2005 Jan 13;24(3):344-54.

49. Zhang $X$, Li W, Wang C, Leng X, Lian S, Feng J, et al. Inhibition of autophagy enhances apoptosis induced by proteasome inhibitor bortezomib in human glioblastoma U87 and U251 cells. Mol Cell Biochem. 2014 Jan;385(1-2):265-75.

50. Demo SD, Kirk CJ, Aujay MA, Buchholz TJ, Dajee M, Ho MN, et al. Antitumor activity of PR171, a novel irreversible inhibitor of the proteasome. Cancer Res. 2007 Jul 1;67(13):6383-91.

51. Gan HK, Kaye AH, Luwor RB. The EGFRvIII variant in glioblastoma multiforme. J Clin Neurosci. 2009 Jun;16(6):748-54.

52. Mishima K, Johns TG, Luwor RB, Scott AM, Stockert E, Jungbluth AA, et al. Growth suppression of intracranial xenografted glioblastomas overexpressing mutant epidermal growth factor receptors by systemic administration of monoclonal antibody (mAb) 806 , a novel monoclonal antibody directed to the receptor. Cancer Res. $2001 \mathrm{Jul}$ 15;61(14):5349-54.

53. Montgomery RB, Guzman J, O'Rourke DM, Stahl WL. Expression of oncogenic epidermal growth factor receptor family kinases induces paclitaxel resistance and alters beta-tubulin isotype expression. J Biol Chem. 2000 Jun 9;275(23):17358-63.

54. Nagane M, Coufal F, Lin H, Bogler O, Cavenee WK, Huang HJ. A common mutant epidermal growth factor receptor confers enhanced tumorigenicity on human glioblastoma cells by increasing proliferation and reducing apoptosis. Cancer Res. 1996 Nov 1;56(21):5079-86.

55. Prigent SA, Nagane M, Lin H, Huvar I, Boss GR, Feramisco JR, et al. Enhanced tumorigenic behavior of glioblastoma cells expressing a truncated epidermal growth factor receptor is mediated through the Ras-Shc-Grb2 pathway. J Biol Chem. 1996 Oct 11;271(41):25639-45.

56. Kim K, Brush JM, Watson PA, Cacalano NA, Iwamoto KS, McBride WH. Epidermal growth factor receptor vIll expression in U87 glioblastoma cells alters their proteasome composition, function, and response to irradiation. Mol Cancer Res. 2008 Mar;6(3):426-34. 
57. Egeblad $M$, Werb Z. New functions for the matrix metalloproteinases in cancer progression. Nat Rev Cancer. 2002 Mar;2(3):161-74.

58. Giannelli G, Falk-Marzillier J, Schiraldi O, Stetler-Stevenson WG, Quaranta V. Induction of cell migration by matrix metalloprotease-2 cleavage of laminin-5. Science. $1997 \mathrm{Jul}$ 11;277(5323):225-8.

59. Musumeci G, Magro G, Cardile V, Coco M, Marzagalli R, Castrogiovanni P, et al. Characterization of matrix metalloproteinase-2 and -9, ADAM-10 and N-cadherin expression in human glioblastoma multiforme. Cell Tissue Res. 2015 Oct;362(1):45-60.

60. Williamson MJ, Blank JL, Bruzzese FJ, Cao Y, Daniels JS, Dick LR, et al. Comparison of biochemical and biological effects of ML858 (salinosporamide A) and bortezomib. Mol Cancer Ther. 2006 Dec;5(12):3052-61.

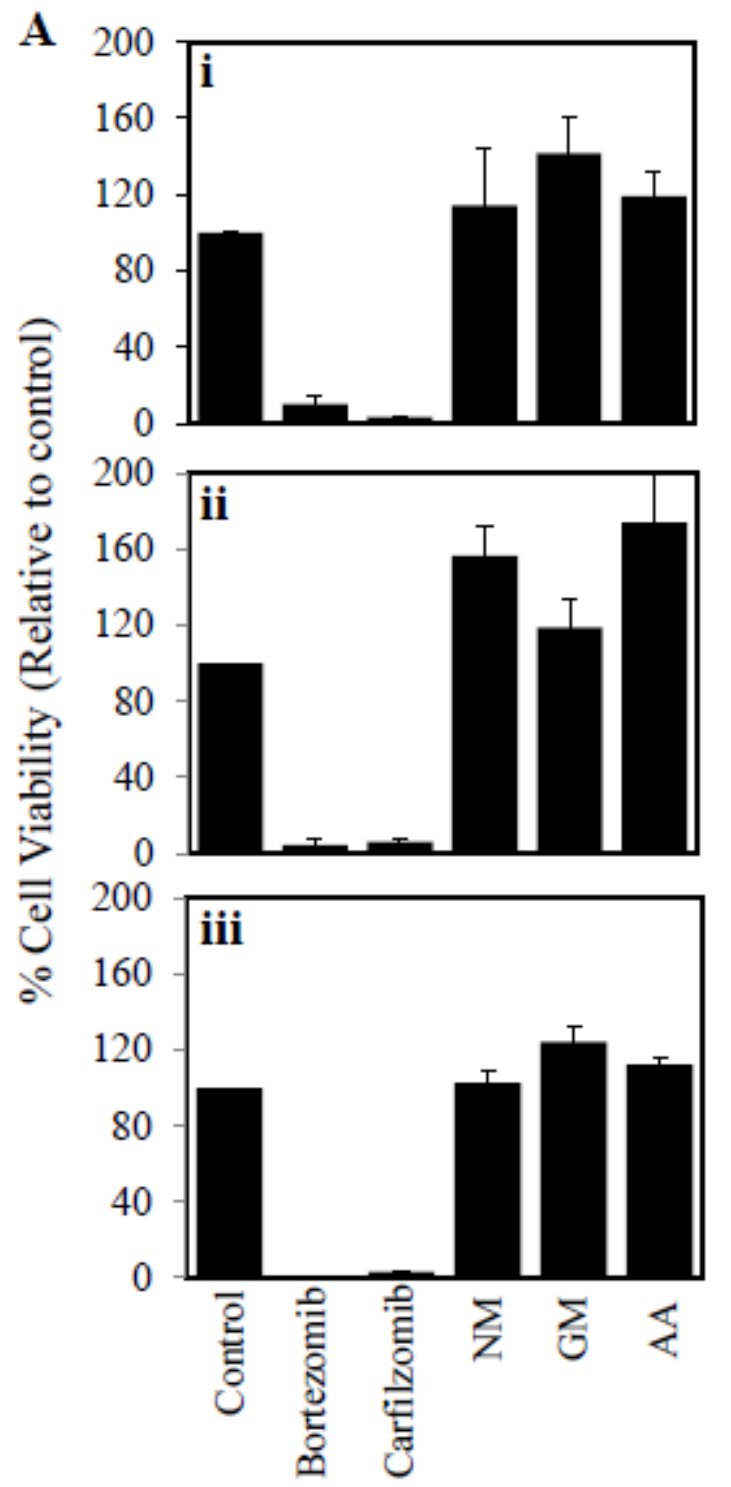

B 120
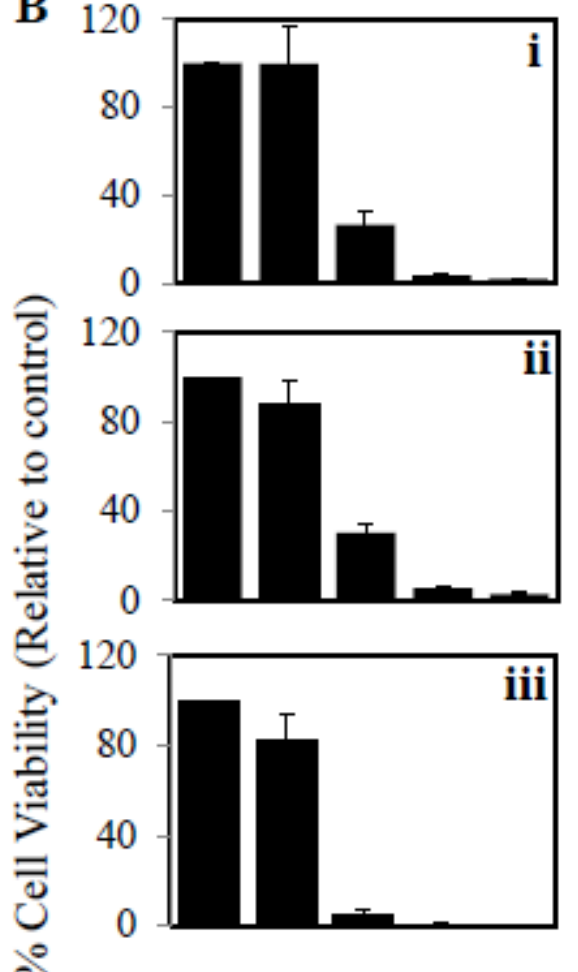

$\circ$

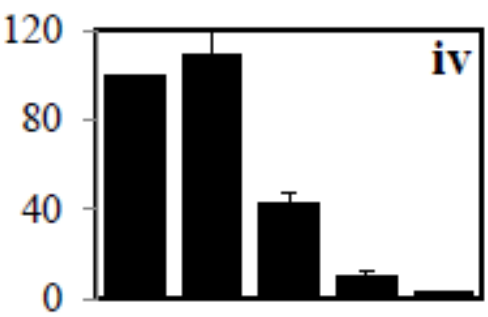

$\begin{array}{llll}\text { Carfilzomib } 0 & 1 & 10 & 1001000\end{array}$

(nM)

Fig. 1 

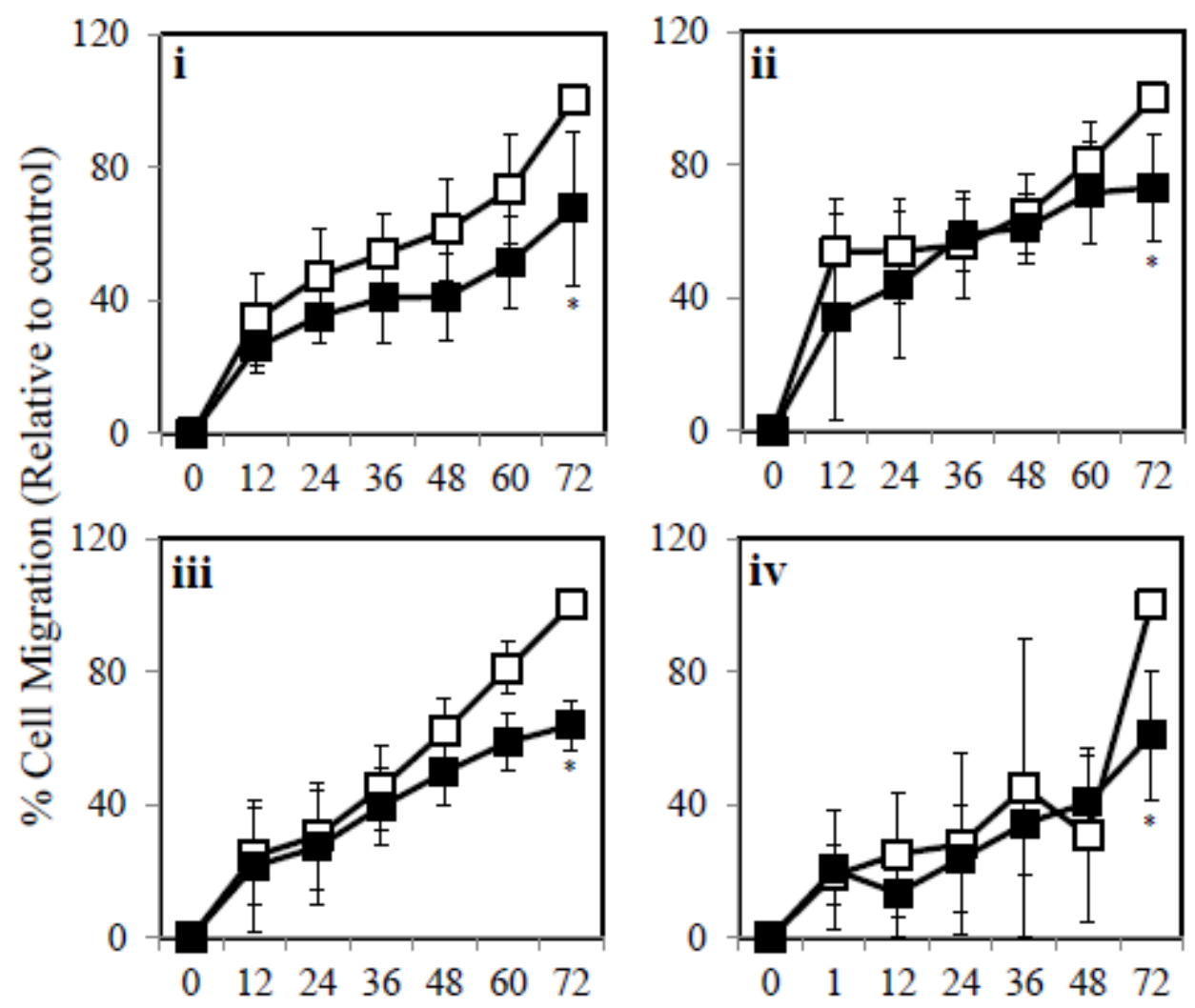

Hrs Post Treatment

Fig. 2

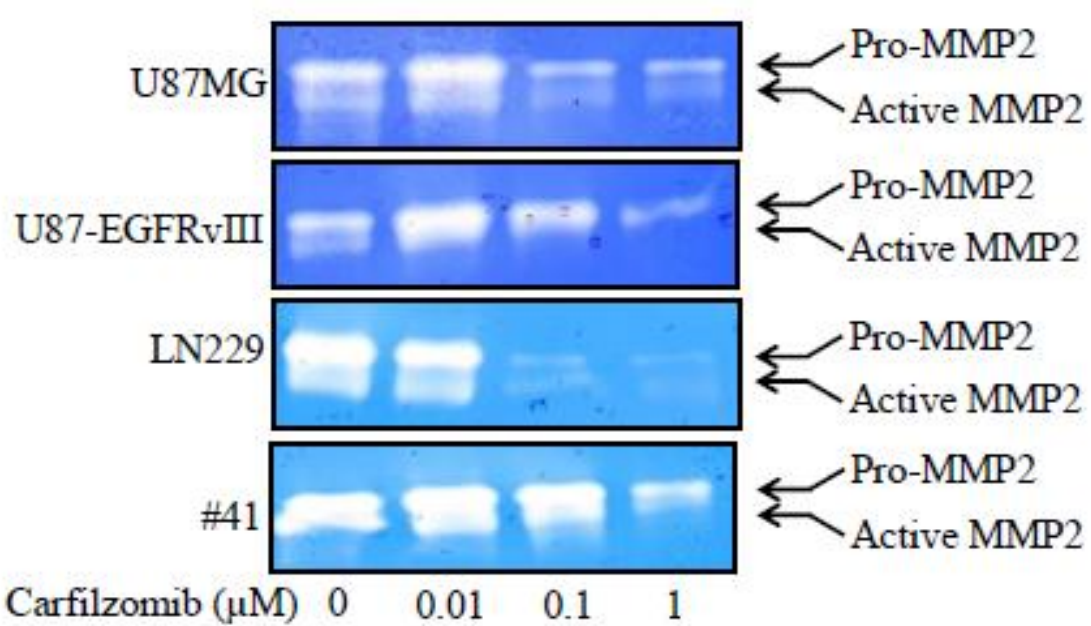

Fig. 3 


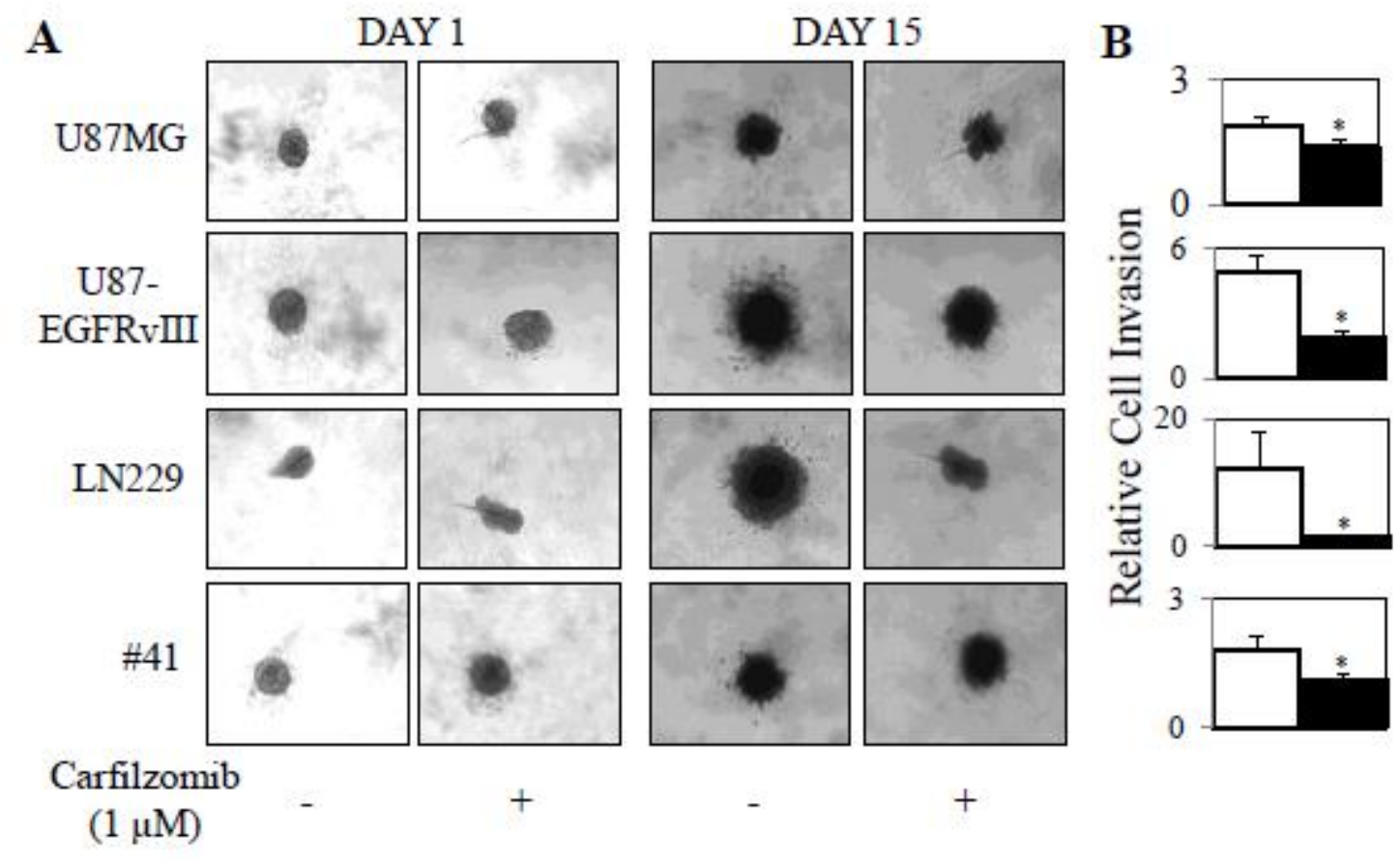

Fig. 4 